\title{
Rationale and design of a randomized controlled trial of varenicline directly observed therapy delivered in methadone clinics
}

Shadi Nahvi ${ }^{1,2^{*}}$, Kate S Segal ${ }^{1}$, Alain H Litwin ${ }^{1,2}$ and Julia H Arnsten ${ }^{1,2,3}$

\begin{abstract}
Background: Tobacco cessation medication adherence is one of the few factors shown to improve smoking cessation rates among methadone-maintained smokers, but interventions to improve adherence to smoking cessation medications have not yet been tested among methadone treatment patients. Methadone clinic-based, directly observed therapy (DOT) programs for HIV and tuberculosis improve adherence and clinical outcomes, but have not been evaluated for smoking cessation. We describe a randomized controlled trial to evaluate whether a methadone clinic-based, directly observed varenicline therapy program increases adherence and tobacco abstinence among opioid-dependent drug users receiving methadone treatment.
\end{abstract}

Methods/Design: We plan to enroll 100 methadone-maintained smokers and randomize them to directly observed varenicline dispensed with daily methadone doses or treatment as usual (self-administered varenicline) for 12 weeks. Our outcome measures are: 1) pill count adherence and 2) carbon monoxide-verified tobacco abstinence. We will assess differences in adherence and abstinence between the two treatment arms using repeated measures models.

Discussion: This trial will allow for rigorous evaluation of the efficacy of methadone clinic-based, directly observed varenicline for improving adherence and smoking cessation outcomes. This detailed description of trial methodology can serve as a template for the development of future DOT programs and can guide protocols for studies among opioid-dependent smokers receiving methadone treatment.

Trial Registration: clinicaltrials.gov NCT01378858

Keywords: Adherence, Smoking cessation, Varenicline, Directly observed therapy, DOT, Methadone, Opioid-related disorders

\section{Background}

Methadone maintenance treatment patients have a disproportionately high prevalence of tobacco use and suffer high rates of tobacco-related disease and mortality [1-6]. Cessation approaches evaluated to date among opioid-dependent smokers, including nicotine replacement therapy, bupropion, or varenicline in combination with behavioral therapy, have not been effective over control conditions [7-11]. Varenicline's demonstrated efficacy may not be generalizable to methadone-maintained

\footnotetext{
* Correspondence: snahvi@montefiore.org

'Department of Medicine, Albert Einstein College of Medicine and

Montefiore Medical Center, 111 East 210th Street, 10467 Bronx, NY, USA

${ }^{2}$ Department of Psychiatry \& Behavioral Sciences, Albert Einstein College of

Medicine, 111 East 210th Street, 10467 Bronx, NY, USA

Full list of author information is available at the end of the article
}

smokers because of poor adherence, which is highly prevalent among drug users [11-15]. Though adherence to smoking cessation treatment is a critical determinant of successful cessation [16-23] and adherence is one of the few factors shown to increase cessation among methadonemaintained smokers $[12,24,25]$, interventions to improve adherence to smoking cessation pharmacotherapy have not yet been tested in this group.

Administration of directly observed therapy (DOT) for tuberculosis (TB) and HIV regimens at opioid agonist treatment programs has been shown to improve adherence and clinical outcomes among methadone maintenance patients [26-30]. Methadone maintenance programs provide an ideal setting for DOT administration. Regulatory requirements mandate that patients attend methadone programs 
up to 6 times weekly, minimizing barriers to medication adherence, and providing a platform for treatment of other diseases. Because of the limited treatment course and low pill burden of smoking cessation treatment, it may be even more feasible to implement DOT for smoking cessation treatment than for TB or HIV treatment. To our knowledge, no studies to date have evaluated DOT for smoking cessation.

We thus designed a randomized trial of modified, directly observed versus self-administered varenicline therapy in methadone clinics to evaluate the efficacy of modified DOT (mDOT) for improving varenicline adherence and smoking cessation among methadone-maintained smokers, and to test whether drug use and psychiatric symptoms moderate the effects of mDOT on adherence.

\section{Methods/Design}

This is a randomized pilot trial of modified directly observed versus self-administered varenicline therapy among 100 methadone-maintained smokers. We will evaluate the efficacy of mDOT varenicline for promoting smoking cessation and medication adherence with research visits at baseline and at $1,2,3,6,9,12$, and 24 weeks. We will also evaluate the moderating effects of illicit drug use and psychiatric symptoms on mDOT adherence effects.

\section{Study setting}

Participants will be recruited from the Einstein Division of Substance Abuse (DoSA) methadone clinics, which offer integrated substance abuse and medical treatment to 3200 patients in three clinical sites in the Bronx, New York. Established in 1968, DoSA is a clinical, research, and educational division of the Einstein Department of Psychiatry. Each clinic offers comprehensive medical services, integrating general and HIV-related medical and gynecologic services with co-located substance abuse treatment.

\section{Participants}

Our goal is to enroll subjects representative of methadonemaintained smokers, while considering varenicline precautions. Eligible persons are: 18 years or older; smoking 5 or more cigarettes per day; interested in quitting smoking with a plan to quit in $\leq 6$ months (ladder of change score 6-8); enrolled in methadone treatment for at least 3 months, receiving methadone in the clinic 3,4 , 5 , or 6 times per week, without three or more clinic absences in the prior 2 weeks; English-speaking; able to provide informed consent; not pregnant, breastfeeding, or trying to conceive; and have not taken varenicline in the past 30 days. Unstable liver, cardiac, pulmonary, renal, or infectious diseases are exclusionary. Psychiatric exclusion criteria include current major depressive or manic episode, current psychotic disorder, past-year suicide attempt or psychiatric hospitalization, or current suicidal ideation with plan or intent.

Subjects will be recruited by research assistants in methadone clinic waiting areas, as well as by word-ofmouth, posted fliers, and clinic counseling and medical staff referral. All subjects will sign written informed consent. We will conduct a brief screening interview, then abstract laboratory and treatment data from clinic charts to further assess eligibility. Eligibility will be confirmed only after the study physician completes a clinical and structured psychiatric interview using the Mini-International Neuropsychiatric Interview 6.0.0 (M.I.N.I.) and Columbia Suicide Severity Rating Scale, and conducts a physical examination and urine pregnancy test (if applicable). Interviews will be completed in private offices in the methadone clinics.

\section{Interventions}

Subjects will receive varenicline for 12 weeks, using standard dosing: $0.5 \mathrm{mg}$ once daily for 3 days, then $0.5 \mathrm{mg}$ twice daily for 4 days, followed by $1 \mathrm{mg}$ twice daily for 11 weeks. Subjects will be randomly assigned to receive varenicline via: 1) treatment as usual (TAU) or 2) modified directly observed therapy (mDOT). Most subjects will have public insurance that should cover the cost of varenicline; for those who do not, varenicline will be purchased from a local pharmacy using research funds.

\section{DOT Intervention}

Subjects in the mDOT arm will receive: 1) directly observed varenicline doses at the same time as they receive a methadone dose at their methadone program, between 3 and 6 times per week; and 2) take-home doses packaged in individual pill boxes for self-administration on days off and evenings (Figure 1). In addition, methadone clinic nurses will assess side effects using a standard script and will refer subjects to on-site medical providers for treatment if side effects are reported.

We describe the intervention as 'modified directly observed therapy' because varenicline ingestion will be observed at the methadone window 3-6 days per week based on the subject's methadone clinic schedule. Furthermore, varenicline is a twice-daily medication, and only one of two daily varenicline doses can be observed. For example, if a subject receives methadone at his/her program Monday through Saturday and a take-home dose of methadone on Sunday, s/he would receive observed varenicline at the same time $\mathrm{s} /$ he receives methadone Monday through Saturday (for a total of six observed doses), and would get pill boxes for evening and Sunday varenicline doses (eight unobserved doses weekly). Subjects will be instructed to return the pill boxes for unobserved doses at their next clinic visit, whether or not they have taken the pills. 
A. Methadone clinic visits three days per week

\begin{tabular}{|c|c|c|c|c|c|c|}
\hline $\begin{array}{c}\text { SUNDAY } \\
\text { Varenicline } 1 \mathrm{mg} \\
\text { Take in AM }\end{array}$ & $\begin{array}{c}\text { MONDAY } \\
\text { Varenicline } 1 \mathrm{mg} \\
\text { Take in AM }\end{array}$ & $\begin{array}{c}\text { TUESDAY } \\
\text { Varenicline } 1 \mathrm{mg} \\
\text { Take in AM }\end{array}$ & $\begin{array}{c}\text { WEDNESDAY } \\
\text { Varenicline } 1 \mathrm{mg} \\
\text { Take in AM }\end{array}$ & $\begin{array}{c}\text { THURSDAY } \\
\text { Varenicline } 1 \mathrm{mg} \\
\text { Take in AM }\end{array}$ & $\begin{array}{c}\text { FRIDAY } \\
\text { Varenicline } 1 \mathrm{mg} \\
\text { Take in AM }\end{array}$ & $\begin{array}{c}\text { SATURDAY } \\
\text { Varenicline } 1 \mathrm{mg} \\
\text { Take in AM }\end{array}$ \\
\hline $\begin{array}{c}\text { SUNDAY } \\
\begin{array}{c}\text { Varenicline } 1 \mathrm{mg} \\
\text { Take in PM }\end{array}\end{array}$ & $\begin{array}{c}\text { MONDAY } \\
\text { Varenicline } 1 \mathrm{mg} \\
\text { Take in PM }\end{array}$ & $\begin{array}{c}\text { TUESDAY } \\
\text { Varenicline } 1 \mathrm{mg} \\
\text { Take in PM }\end{array}$ & $\begin{array}{c}\text { WEDNESDAY } \\
\text { Varenicline } 1 \mathrm{mg} \\
\text { Take in PM }\end{array}$ & $\begin{array}{c}\text { THURSDAY } \\
\text { Varenicline } 1 \mathrm{mg} \\
\text { Take in PM }\end{array}$ & $\begin{array}{c}\text { FRIDAY } \\
\text { Varenicline } 1 \mathrm{mg} \\
\text { Take in PM }\end{array}$ & $\begin{array}{c}\text { SATURDAY } \\
\text { Varenicline } 1 \mathrm{mg} \\
\text { Take in PM }\end{array}$ \\
\hline
\end{tabular}

B. Methadone clinic visits six days per week

\begin{tabular}{|c|c|c|c|c|c|c|}
\hline $\begin{array}{c}\text { SUNDAY } \\
\text { Varenicline } 1 \mathrm{mg} \\
\text { Take in AM }\end{array}$ & $\begin{array}{c}\text { MONDAY } \\
\text { Varenicline } 1 \mathrm{mg} \\
\text { Take in AM }\end{array}$ & $\begin{array}{c}\text { TUESDAY } \\
\text { Varenicline } 1 \mathrm{mg} \\
\text { Take in AM }\end{array}$ & $\begin{array}{c}\text { WEDNESDAY } \\
\text { Varenicline } 1 \mathrm{mg} \\
\text { Take in AM }\end{array}$ & $\begin{array}{c}\text { THURSDAY } \\
\text { Varenicline } 1 \mathrm{mg} \\
\text { Take in AM }\end{array}$ & $\begin{array}{c}\text { FRIDAY } \\
\text { Varenicline } 1 \mathrm{mg} \\
\text { Take in AM }\end{array}$ & $\begin{array}{c}\text { SATURDAY } \\
\text { Varenicline } 1 \mathrm{mg} \\
\text { Take in AM }\end{array}$ \\
\hline $\begin{array}{c}\text { SUNDAY } \\
\begin{array}{c}\text { Varenicline } 1 \mathrm{mg} \\
\text { Take in PM }\end{array}\end{array}$ & $\begin{array}{c}\text { MONDAY } \\
\text { Varenicline } 1 \mathrm{mg} \\
\text { Take in PM }\end{array}$ & $\begin{array}{c}\text { TUESDAY } \\
\text { Varenicline } 1 \mathrm{mg} \\
\text { Take in PM }\end{array}$ & $\begin{array}{c}\text { WEDNESDAY } \\
\text { Varenicline } 1 \mathrm{mg} \\
\text { Take in PM }\end{array}$ & $\begin{array}{c}\text { THURSDAY } \\
\text { Varenicline } 1 \mathrm{mg} \\
\text { Take in PM }\end{array}$ & $\begin{array}{c}\text { FRIDAY } \\
\text { Varenicline } 1 \mathrm{mg} \\
\text { Take in PM }\end{array}$ & $\begin{array}{c}\text { SATURDAY } \\
\text { Varenicline } 1 \mathrm{mg} \\
\text { Take in PM }\end{array}$ \\
\hline
\end{tabular}

Observed doses

Take home doses

Figure 1 Example mDOT varenicline pill trays. A. Methadone clinic visits 3 days per week. B. Methadone clinic visits 6 days per week. This figure illustrates mDOT varenicline pill box labels indicating observed and take-home varenicline doses, according to subjects' methadone clinic schedule.

To minimize nursing burden, trays of pill boxes will be prepared by research assistants, indicating varenicline dosing and dates of administration, and color-coded labels will indicate whether the dose is directly observed or self-administered (for days off and evenings). Each tray will hold seven removable pill boxes, with compartments for morning and evening varenicline doses. The study physician will call in varenicline prescriptions to a single, designated, community pharmacy that delivers medications to the DoSA central pharmacy. Empty, labeled trays also will be delivered to the central DoSA pharmacist, who will fill pill boxes with varenicline for each subject. Filled trays will be delivered from the central pharmacy to the methadone clinics every 2 weeks, along with scheduled methadone deliveries.

\section{TAU Control condition}

Subjects in the TAU arm will pick up prescribed varenicline from a local pharmacy of their choosing and selfadminister all varenicline doses (once daily for 3 days, then twice daily).

\section{Counseling and medication education}

All subjects in both groups will receive a single session of brief, physician, smoking cessation counseling based on the Public Health Service 5As framework (ask, assess, advise, assist, arrange follow-up) [31]. Brief advice has been shown to increase the likelihood of successful smoking cessation [31], is associated with outcomes comparable to tailored motivational counseling among methadone- maintained smokers [8], and is easily implemented in complex clinical settings. Subjects also will receive a brochure promoting medication adherence, as well as verbal and written instructions on varenicline administration and management of anticipated side effects. If subjects report persistent or severe treatment-emergent symptoms over the intervention period, they will meet with the study physician for assessment and brief counseling on symptom management.

\section{Randomization}

Subjects will be randomized a 1:1 ratio in variable size blocks of 2-8 via central, computer-generated randomization. Randomization will be stratified by clinical site and HIV status. We will randomize in blocks to ensure comparison groups of approximately equal size. To ensure concealment of allocation, a centrally-located data manager will generate the allocation sequence and store the sequence in a password-protected file. After the study physician confirms a subject's eligibility, she will call the data manager, who will assign the subject to a treatment group. Since the intervention is not blinded, we will vary block size to prevent anticipation of treatment arm assignment.

\section{Visit schedule and measures}

Research visits will be scheduled at baseline and at weeks $1,2,3,6,9,12$, and 24 (Table 1). We will collect survey data using Audio Computer-Assisted Self-Interview (ACASI), which has been shown to improve reporting of 
Table 1 Timing of study measures

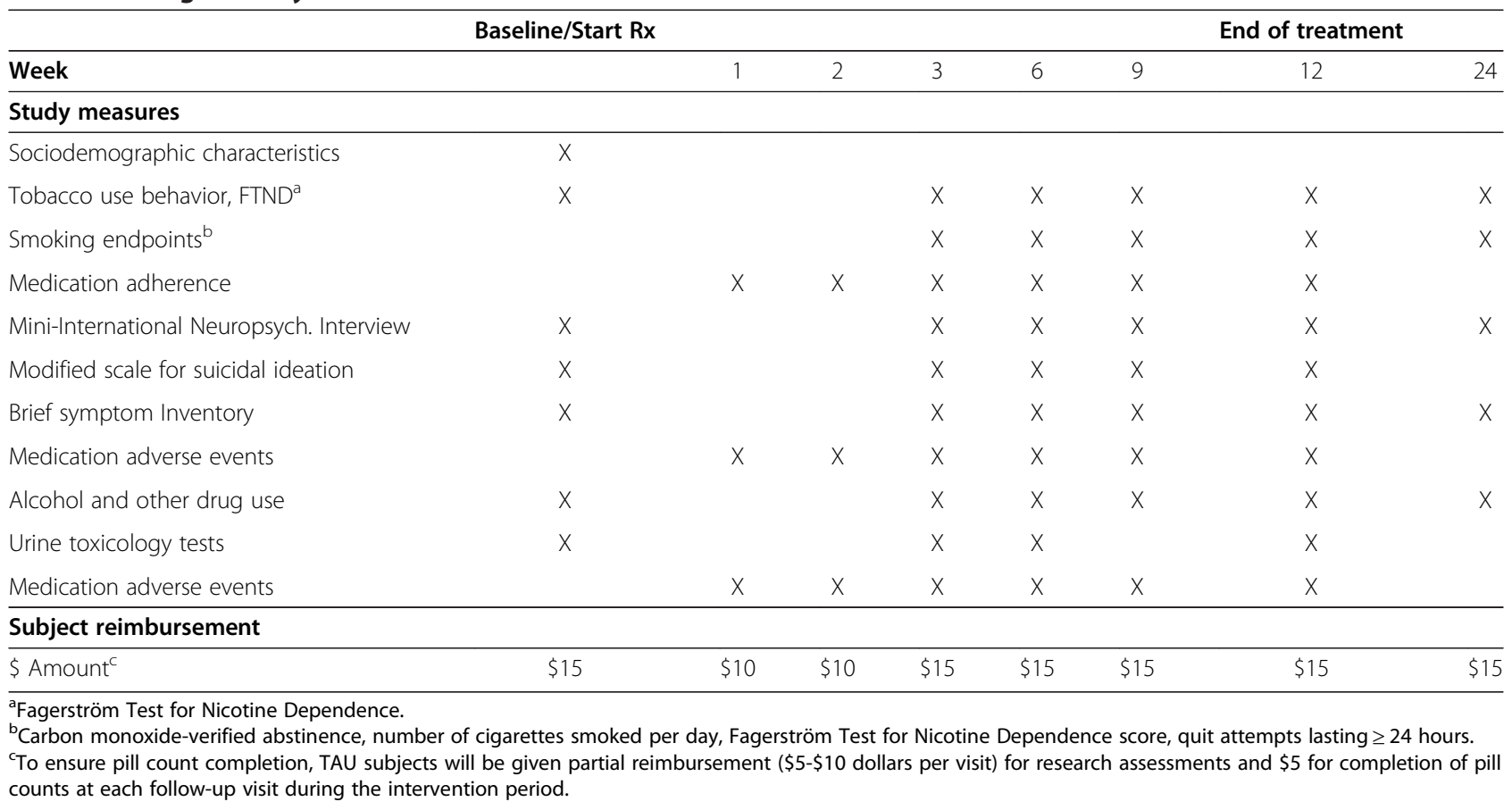

stigmatized behaviors. Subjects will be reimbursed up to $\$ 110$ for completing all research assessments. Retention will be enhanced by flagging subjects for research visits at the methadone clinic reception desk, tracking contact information of subjects and their close contacts at each study visit, reimbursement for completion of assessments, and on-site data collection at subjects' clinics.

\section{Adherence measures}

Our primary outcome is adherence (as a continuous measure) by pill count. Pill counts are an objective measure that have been shown to correlate with electronic monitors [32]. The amount of medication taken during the 12-week treatment course will be expressed as a percentage of the target dose. These are established measures used in other DOT trials in our setting [29,33]. Self-report is the most practical adherence measure for clinical use, and it has been shown to correlate with clinically relevant outcomes in several studies [34-37]. Though self-report is subject to recall and reporting bias and may overestimate adherence $[32,36,38,39]$, we will use self-report as a second measure of adherence because it is easy to administer and is generalizable. Because electronic monitors (using medication event monitoring systems [MEMs]) cannot be used in the mDOT arm, we have chosen not to use MEMs.

\section{Tobacco use measures}

Our primary tobacco use outcome is biochemically validated 7-day point prevalence abstinence at each follow-up visit, with abstinence defined as including both self- reported smoking abstinence and carbon monoxide (CO) $<8$ p.p.m. (Micro Smokerlyzer ${ }^{\oplus}$ Bedfont Scientific) [40]. Self-reported tobacco abstinence will be measured at all visits by asking participants, "Have you smoked at least part of a cigarette in the past 7 days, even a puff?" Our secondary tobacco outcome measures include: 1) number of cigarettes smoked per day; 2) Fagerström Test for Nicotine Dependence score; 3) quit attempts lasting $\geq 24$ hours; and 4) durability, measured by COverified tobacco abstinence at week 24 .

\section{Potential moderating variables: psychologic symptoms}

We will assess incident psychologic symptoms at weeks 3, 6, 9, and 12 using: 1) M.I.N.I. [41], which is a short, structured, diagnostic interview for DSM-IV Axis I disorders; 2) the Columbia Suicide Severity Rating Scale, a structured interview that assesses suicidal ideation, plans, intent, and behavior [42]; and 3) the Brief Symptom Inventory (BSI [43]), a measure of general psychological symptom status that can be monitored over time.

\section{Potential moderating variables: Alcohol and drug use}

We will assess alcohol and drug use at baseline and at weeks 3, 6, 9, and 12 via: 1) the Addiction Severity Index, Lite version [44]; 2) the Alcohol Use Disorders Identification Test [45]; and 3) urine toxicology tests.

\section{Medication adverse effects}

Adverse events will be evaluated at each follow-up visit during the intervention period, using both a structured 
questionnaire that assesses the presence of specific symptoms that have been reported among varenicline subjects in published clinical trials, and an open-ended review of treatment-emergent symptoms, defined as symptoms that emerged or increased in intensity following the start of study medication.

\section{Major hypotheses and analytic plans}

We will review and summarize data using descriptive summaries and graphical analyses to ensure recorded values are within appropriate ranges and to check for outliers and abnormal values. Interim analyses will not guide recruitment decisions.

\section{Varenicline adherence}

We hypothesize that adherence in the mDOT arm will be higher than in the TAU arm throughout the intervention period. We will apply a mixed effects linear model to test the significance of the mDOT effect on the repeatedly measured pill count adherence outcome at weeks 1, 2, 3, 6, 9, and 12. This model accounts for within-subject longitudinal outcome correlation by taking the subject-level intercept as random, and it is robust in the context of missing data. The model will also include variables not equally distributed between the study arms at baseline, as well as psychiatric symptoms and substance abuse. All analyses will use an intent-totreat approach.

\section{Tobacco use}

We hypothesize subjects in the mDOT arm will have greater CO-verified, 7-day point prevalence abstinence throughout the intervention period; reductions in cigarettes/day and Fagerström Test for Nicotine Dependence scores; and $\geq 24$-hour quit attempts compared to subjects receiving self-administered varenicline. We will compare the proportion of participants who achieve $\mathrm{CO}$-verified tobacco abstinence at all follow-up timepoints in the two study arms using mixed-effects models. In addition, we will compare secondary tobacco use outcomes between study arms using chi-square or Wilcoxon rank sum tests, and explore differences in CO-verified abstinence at 24 weeks using Fisher exact tests. All analyses will use an intent-to-treat approach. In addition, we will apply mixed effects models to test the significance of varenicline adherence on smoking cessation across the post-baseline assessment time points.

Moderating effects of drug use and psychiatric symptoms We hypothesize that ongoing drug use and psychiatric symptoms will negatively moderate adherence effects. The dependent variable will be varenicline adherence. Potential moderating variables include cocaine, heroin, benzodiazepine, or marijuana use (defined as a binary variable based on either self-reported use or positive urine toxicology result); hazardous alcohol use (defined as AUDIT score $\geq 8$ for men and $\geq 4$ for women); incident major depressive, manic, or psychotic episodes; suicidal ideation with plan or intent; and symptoms of psychologic distress (BSI Global Severity Index $\mathrm{T}$ score $\geq 63$ ). We will test moderators using a treatment group $\mathrm{x}$ moderating variable interaction term, and set an alpha significance level of 0.15 for interaction analyses.

\section{Sample size and power considerations}

Among methadone-maintained smokers receiving a nicotine patch in a clinical trial, overall adherence over 90 days was 44.1 percent [12]. Assuming a 13-percent difference in adherence between the DOT and TAU groups as seen in weeks 2-12 of a methadone clinic-based antiretroviral DOT trial [30], the hypothesized adherence effect would be 57 percent in the $\mathrm{mDOT}$ arm and 44 percent in the TAU arm. We estimate sample sizes $\mathrm{N}$ per group required to detect this effect at a two-sided $\alpha=0.05$ as $\mathrm{N}$ per group $=11,14$, and 17 for intraclass correlation $(\mathrm{ICC})=0.1,0.2$, and 0.3 , respectively.

Given that the efficacy of NRT and bupropion in methadone maintenance patients has been half of that observed in clinical trials of these medications in the general population $[7,8,15]$, we estimate that abstinence rates at 12 weeks in the TAU varenicline arm would be 22 percent. We estimate that increased adherence would double the odds of cessation $[13,17,18,46]$, and thus the abstinence rates at 12 weeks in the DOT arm would be 44 percent. We estimate sample sizes required to detect the hypothesized intervention effect (22\% and $44 \%$ on a binary scale) at a two-sided alpha $=0.05$ as $\mathrm{N}$ per group $=29,33,38$ for within-subject $\mathrm{ICC}=0.1,0.2$, and 0.3 , respectively. Estimating an approximately 25 percent attrition rate at 12 weeks, we plan to recruit 100 participants.

\section{Dissemination policy}

We will disseminate study findings at national scientific meetings and in published manuscripts. On request, we will also share study protocols and de-identified study data with investigators for research purposes. No study participants will be individually identified in any published or shared data.

\section{Study design considerations Optimizing pill count adherence measurement}

For mDOT arm subjects, varenicline dosing will be evaluated by directly counting unconsumed varenicline pills remaining behind the methadone window, as well as those returned to nurses in pill boxes. Unobserved doses in unreturned pill boxes will be counted as nonadherence. Each day, nurses also will complete a pre-printed 
calendar documenting whether doses were dispensed, refused, or if the subject missed clinic.

Since a 4-week supply of $1 \mathrm{mg}$ varenicline tablets can be dispensed in bottles (containing 56 tablets) or in four weekly blister packs (each containing 14 tablets), TAU group subjects will be asked to bring in the full month's supply of medication to each study visit for pill counting. For TAU arm subjects, research assistants will count pills remaining in varenicline bottles or blister packs at weeks $1,2,3,6,9$, and 12 . Given that TAU subjects obtain a 4-week supply of medication at a time from community pharmacies, and that pill-count adherence would be challenging to interpret if no pills were remaining, we designed the research visit schedule to assess pill count adherence separately from the every-4-week medication dispensing intervals. To ensure pill count completion, TAU group subjects will be given partial reimbursement (\$5-\$10 dollars per visit) for completion of research assessments and $\$ 5$ for completion of pill counts at each follow-up visit during the intervention period.

\section{Protection of study subjects Confidentiality and research protections}

The trial was approved by the Einstein Committee on Clinical Investigations. All subjects will complete an informed consent process and provide written consent. We also obtained a Certificate of Confidentiality from the National Institute on Drug Abuse to protect against disclosure of research information in federal, state, or local civil, criminal, or administrative proceedings. We established a Data Safety and Monitoring Committee (DSMC), composed of two senior clinical investigators with expertise in clinical trials. We will report trial progress to the DSMC quarterly, along with incident psychiatric illness, serious or unanticipated adverse events, pregnancies, and protocol deviations, and we will meet formally twice a year.

\section{Addressing varenicline risk potential}

Case reports of behavior change, agitation, depression, and suicidality among patients taking varenicline led to an FDA boxed warning in 2009 [47]. Despite a growing body of research demonstrating the safety of varenicline among patients with mental illness and substance use disorders [48-56], we will take multiple precautions to address varenicline's psychiatric risk potential.

Prior to enrollment, information regarding potential psychiatric risks will be discussed with subjects during the informed consent process. During screening, a physician will assess potential subjects for current psychiatric illness or suicidal ideation using structured instruments. Individuals with psychiatric symptoms not receiving psychiatric care will be referred to a mental health center.

Subjects will be assessed for incident psychiatric symptoms throughout the intervention period. At brief visits (weeks 1 and 2), and weeks 3, 6, 9 and 12, the interviewer will ask open-ended questions about symptoms that have emerged or increased in intensity since the prior visit. At week 3, 6, 9, and 12 follow-up visits, psychiatric symptoms will be assessed via structured instruments. Prior to concluding the research visit, the research assistant will review flags programmed into the computerized survey record for symptoms consistent with incident major depressive or manic episode, psychotic disorder, or suicidal ideation and will refer subjects to outpatient or emergency treatment according to detailed study protocols.

If subjects meet criteria for current major depressive or manic episode, psychotic disorder, or suicidal ideation with plan or intent, varenicline will be discontinued. To facilitate medication discontinuation among TAU group subjects who fill varenicline prescriptions at community pharmacies of their choosing, prescriptions will not be given directly to study subjects; rather, the study physician will call in all prescriptions and track the pharmacies used. If DOT group subjects meet criteria for medication discontinuation, the study physician will notify the study pharmacy and the methadone clinic nurses.

\section{Discussion}

This study represents the first randomized controlled trial of directly observed smoking cessation treatment in a methadone program. Our trial draws on prior work demonstrating the feasibility and efficacy of directly observed HIV and TB treatment [26-30] and extends this research to evaluate smoking cessation medication. Outcomes from this trial will contribute to knowledge about whether varenicline DOT is efficacious at promoting adherence and smoking cessation among methadone maintenance patients.

Multiple studies suggest that smoking cessation medication adherence is an important determinant of cessation success [16-21], including among methadone-maintained smokers [12,24,25]. In a retrospective cohort study in which methadone maintenance patients were prescribed varenicline during routine clinical care, varenicline treatment duration was significantly associated with smoking cessation [25]. In two large smoking cessation trials among methadone maintenance patients, adherence to nicotine patch treatment was also shown to be associated with improved smoking cessation outcomes [12,24]. Methadonemaintained smokers had fewer cigarettes per day and a $7.1 \mathrm{x}$ increased odds of abstinence on days in which they used patches compared to days they did not [12]. This supports the importance of developing and evaluating interventions to promote varenicline adherence.

Our trial has several strengths. Participants will be randomly assigned to receive DOT or self-administered varenicline. We will use objective measures of both adherence and smoking cessation. The core components of 
our DOT program will not require additional funding over existing clinic operating budgets. We will not provide salary support for nurses, and medications will be paid for by subjects' existing insurance plans. We will supply pill boxes used for DOT, and we will pay the DoSA central pharmacist a stipend for filling the pill boxes.

This study also has limitations. Reasons for medication nonadherence are multifaceted. While a DOT strategy cannot address many potential adherence barriers, DOT interventions have demonstrated efficacy for improving adherence and clinical outcomes in TB and HIV. Generalizability to opioid-dependent persons outside of drug treatment may be limited. Nonetheless, over 200,000 people are enrolled in methadone programs in the US, over 80 percent of methadone maintenance patients smoke, and a significant number of methadone programs offer linked primary care services, including TB and HIV care. Furthermore, if proven effective, a DOT model could be used in other inpatient and outpatient substance abuse treatment settings. Finally, our modest sample size may not allow us to definitively evaluate moderating variables or to compare tobacco abstinence rates between the $\mathrm{mDOT}$ and TAU groups for smaller effect sizes. When we designed this study, there were no published studies on varenicline effects among methadone-maintained smokers. We have since completed a placebo-controlled trial of varenicline without DOT, in which 10.5 percent of varenicline-treated subjects were abstinent [57]. In another trial of varenicline, only 4 percent of methadone-maintained smokers achieved abstinence at the end of treatment [11].

Despite these potential limitations, we feel that our design will allow for a controlled evaluation of intervention effects, and our sample size will be adequate to assess adherence in both arms and to inform effect size estimation for future studies of smoking cessation interventions among methadone maintenance patients. Even if the cessation effect of this intervention is small, the potential health impact may be large, given the high prevalence of tobacco use and tobacco-related illness in substance abuse treatment patients.

This study has the potential to improve smoking cessation treatment outcomes and to inform the dissemination of smoking cessation services among substance abuse treatment patients. This, in turn, may reduce the disproportionate prevalence and associated disease burden of tobacco use in this difficult-to-treat group.

\section{Abbreviations}

DOT: Directly observed therapy; mDOT: Modified directly observed therapy; TAU: Treatment as usual; DoSA: Division of Substance Abuse (Albert Einstein College of Medicine).

\section{Competing interests}

The authors declare that they have no competing interests.

\section{Authors' contributions}

SN and JA designed the study, KS and AL made substantial contributions to study design, and SN wrote the first draft of the manuscript. All authors contributed to manuscript preparation and have read and approved the final manuscript.

\section{Acknowledgements}

This work was supported by National Institute on Drug Abuse grants K23 DA025736 to SN, and R25 DA023021 to SN and JHA, and the Einstein Center for AIDS Research. Sponsors had no role in study design; in the collection, analysis, and interpretation of data; in the writing of this manuscript; and in the decision to submit the manuscript for publication. The authors thank Sarah Church, Michael Ciofoletti, Chinazo Cunningham, Xia Ha, Joe Hecht, Moonseong Heo, Marla Keller, Laurel Mohrmann, Yuming Ning, Ingrid Symes, Jeremy Ann Turton, Marie Trombetta, Bryan Wu, Port Morris Pharmacy, and the Division of General Internal Medicine Substance Abuse Affinity Group for assistance with trial administration, data management, and manuscript preparation and review. This trial is dependent on the contributions of Einstein Division of Substance Abuse medical providers, nurses, and patients.

\section{Author details}

'Department of Medicine, Albert Einstein College of Medicine and Montefiore Medical Center, 111 East 210th Street, 10467 Bronx, NY, USA. ${ }^{2}$ Department of Psychiatry \& Behavioral Sciences, Albert Einstein College of Medicine, 111 East 210th Street, 10467 Bronx, NY, USA. ${ }^{3}$ Department of Epidemiology \& Population Health, Albert Einstein College of Medicine, 10467 Bronx, NY, USA.

Received: 19 December 2013 Accepted: 8 April 2014

Published: 13 June 2014

\section{References}

1. Centers for Disease Control and Prevention: State-specific prevalence of cigarette smoking among adults and quitting among persons aged 18-35 years-United States, 2006. MMWR 2007, 56:993-996.

2. Nahvi S, Richter K, Li X, Modali L, Arnsten J: Cigarette smoking and interest in quitting in methadone maintenance patients. Addict Behav 2006, 31:2127-2134.

3. Hurt RD, Offord KP, Croghan IT, Gomez-Dahl L, Kottke TE, Morse RM, Melton L 3rd: Mortality following inpatient addictions treatment. Role of tobacco use in a community-based cohort. JAMA 1996, 275:1097-1103.

4. Hser YI, McCarthy WJ, Anglin MD: Tobacco use as a distal predictor of mortality among long-term narcotics addicts. Prev Med 1994, 23:61-69.

5. Richter KP, Gibson CA, Ahluwalia JS, Schmelzle KH: Tobacco use and quit attempts among methadone maintenance clients. Am J Public Health 2001, 91:296-299.

6. Smyth B, Hoffman V, Fan J, Hser Y-I: Years of potential life lost among heroin addicts 33 years after treatment. Prev Med 2007, 44:369-374.

7. Shoptaw S, Rotheram-Fuller E, Yang X, Frosch D, Nahom D, Jarvik ME, Rawson RA, Ling W: Smoking cessation in methadone maintenance. Addiction 2002, 97:1317-1328.

8. Stein MD, Weinstock MC, Herman DS, Anderson BJ, Anthony UL, Niaura R: A smoking cessation intervention for the methadone-maintained. Addiction 2006, 101:599-607.

9. Reid MS, Fallon B, Sonne S, Flammino F, Nunes EV, Jiang H, Kourniotis E, Lima J, Brady R, Burgess C, Arfken C, Pihlgren E, Giordano L, Starosta A, Robinson J, Rotrosen J: Smoking cessation treatment in communitybased substance abuse rehabilitation programs. I Subst Abuse Treat 2008, 35:68-77.

10. Mooney ME, Poling J, Gonzalez G, Gonsai K, Kosten T, Sofuoglu M: Preliminary study of buprenorphine and bupropion for opioid-dependent smokers. Am J Addict 2008, 17:287-292.

11. Stein MD, Caviness CM, Kurth ME, Audet D, Olson J, Anderson BJ: Varenicline for smoking cessation among methadone-maintained smokers: a randomized clinical trial. Drug Alcohol Depend 2013, 133:486-493.

12. Stein MD, Anderson BJ, Niaura R: Nicotine replacement therapy: patterns of use after a quit attempt among methadone-maintained smokers. J Gen Intern Med 2006, 21:753-757.

13. Stein MD, Anderson BJ, Niaura R: Smoking cessation patterns in methadonemaintained smokers. Nicotine Tob Res 2007, 9:421-428. 
14. Arnsten JH, Demas PA, Grant RW, Gourevitch MN, Farzadegan H, Howard AA, Schoenbaum EE: Impact of active drug use on antiretroviral therapy adherence and viral suppression in HIV-infected drug users. J Gen Intern Med 2002, 17:377-381.

15. Richter KP, McCool RM, Catley D, Hall M, Ahluwalia JS: Dual pharmacotherapy and motivational interviewing for tobacco dependence among drug treatment patients. J Addict Dis 2005, 24:79-90.

16. Halperin AC, McAfee TA, Jack LM, Catz SL, McClure JB, Deprey TM, Richards J, Zbikowski SM, Swan GE: Impact of symptoms experienced by varenicline users on tobacco treatment in a real world setting. J Subst Abuse Treat 2009, 36:428-434

17. Cummings KM, Hyland A, Ockene JK, Hymowitz N, Manley M: Use of the nicotine skin patch by smokers in 20 communities in the United States, 1992-1993. Tob Control 1997, 6(Suppl 2):S63-S70.

18. Shiffman S, Sweeney CT, Ferguson SG, Sembower MA, Gitchell JG: Relationship between adherence to daily nicotine patch use and treatment efficacy: secondary analysis of a 10-week randomized, double-blind, placebocontrolled clinical trial simulating over-the-counter use in adult smokers. Clin Ther 2008, 30:1852-1858.

19. Lam T-H, Abdullah AS, Chan SS, Hedley AJ, Hong Kong Council on Smoking and Health Smoking Cessation Health Centre Steering Group: Adherence to nicotine replacement therapy versus quitting smoking among Chinese smokers: a preliminary investigation. Psychopharmacology (Berl) 2005, 177:400-408.

20. Jolicoeur DG, Ahluwalia JS, Richter KP, Mosier M, Harris KJ, Gibson C, Moranetz CA: The use of nicotine patches with minimal intervention. Prev Med 2000, 30:504-512.

21. Blak BT, Wilson K, Metcalfe M, Maguire A, Hards M: Evaluation of varenicline as an aid to smoking cessation in UK general practice - a THIN database study. Curr Med Res Opin 2010, 26:861-870.

22. Catz SL, Jack LM, McClure JB, Javitz HS, Deprey M, Zbikowski SM, McAfee T, Richards J, Swan GE: Adherence to varenicline in the COMPASS smoking cessation intervention trial. Nicotine Tob Res 2011, 13:361-368.

23. Hays JT, Leischow SJ, Lawrence D, Lee TC: Adherence to treatment for tobacco dependence: association with smoking abstinence and predictors of adherence. Nicotine Tob Res 2010, 12:574-581.

24. Frosch DL, Nahom D, Shoptaw S: Optimizing smoking cessation outcomes among the methadone-maintained. J Subst Abuse Treat 2002, 23:425-430.

25. Nahvi S, Wu B, Richter KP, Bernstein SL, Arnsten JH: Low incidence of adverse events following varenicline initiation among opioid dependent smokers with comorbid psychiatric illness. Drug Alcohol Depend 2013, $132: 47-52$.

26. Gourevitch MN, Wasserman W, Panero MS, Selwyn PA: Successful adherence to observed prophylaxis and treatment of tuberculosis among drug users in a methadone program. J Addict Dis 1996, 15:93-104.

27. Lucas GM, Weidle PJ, Hader S, Moore RD: Directly administered antiretroviral therapy in an urban methadone maintenance clinic: a nonrandomized comparative study. Clin Infect Dis 2004, 38(Suppl 5):S409-S413.

28. Lucas GM, Mullen BA, Weidle PJ, Hader S, McCaul ME, Moore RD: Directly administered antiretroviral therapy in methadone clinics is associated with improved HIV treatment outcomes, compared with outcomes among concurrent comparison groups. Clin Infect Dis 2006, 42:1628-1635.

29. Berg KM, Mouriz J, Li X, Duggan E, Goldberg U, Arnsten JH: Rationale, design, and sample characteristics of a randomized controlled trial of directly observed antiretroviral therapy delivered in methadone clinics. Contemp Clin Trials 2009, 30:481-489.

30. Berg KM, Litwin A, Li X, Heo M, Arnsten JH: Directly observed antiretroviral therapy improves adherence and viral load in drug users attending methadone maintenance clinics: a randomized controlled trial. Drug Alcohol Depend 2011, 113:192-199.

31. Agency for Healthcare Research and Quality: Treating Tobacco Use and Dependence. Clinical Practice Guideline. http://bphc.hrsa.gov/buckets/ treatingtobacco.pdf.

32. Liu H, Golin CE, Miller LG, Hays RD, Beck CK, Sanandaji S, Christian J, Maldonado T, Duran D, Kaplan AH, Wenger NS: A comparison study of multiple measures of adherence to HIV protease inhibitors.[see comment][erratum appears in Ann Intern Med 2002 Jan 15;136(2):175]. Ann Intern Med 2001, 134:968-977.

33. Litwin AH, Berg KM, Li X, Hidalgo J, Arnsten JH: Rationale and design of a randomized controlled trial of directly observed hepatitis $C$ treatment delivered in methadone clinics. BMC Infect Dis 2011, 11:315.
34. Toll BA, McKee SA, Martin DJ, Jatlow P, O'Malley SS: Factor structure and validity of the Medication Adherence Questionnaire (MAQ) with cigarette smokers trying to quit. Nicotine Tob Res 2007, 9:597-605.

35. Wagner JH, Justice AC, Chesney M, Sinclair G, Weissman S, Rodriguez-Barradas M, VACS 3 Project Team: Patient- and provider-reported adherence: toward a clinically useful approach to measuring antiretroviral adherence. J Clin Epidemio/ 2001, 54(Suppl 1):S91-S98.

36. Arnsten JH, Demas PA, Farzadegan H, Grant RW, Gourevitch MN, Chang CJ, Buono D, Eckholdt H, Howard AA, Schoenbaum EE: Antiretroviral therapy adherence and viral suppression in HIV-infected drug users: comparison of self-report and electronic monitoring. Clin Infect Dis 2001, 33:1417-1423.

37. Nieuwkerk PT, Oort FJ: Self-reported adherence to antiretroviral therapy for HIV-1 infection and virologic treatment response: a meta-analysis. J Acquir Immune Defic Syndr 2005, 38:445-448.

38. Waterhouse DM, Calzone KA, Mele C, Brenner DE: Adherence to oral tamoxifen: a comparison of patient self-report, pill counts, and microelectronic monitoring. J Clin Oncol 1993, 11:1189-1197.

39. Wagner GJ: Predictors of antiretroviral adherence as measured by self-report, electronic monitoring, and medication diaries. AIDS Patient Care STDS 2002, 16:599-608.

40. Hughes JR, Keely JP, Niaura RS, Ossip-Klein DJ, Richmond RL, Swan GE: Measures of abstinence in clinical trials: issues and recommendations. Nicotine Tob Res 2003, 5:13-25.

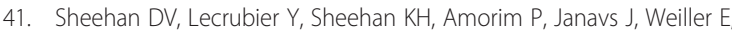
Hergueta T, Baker R, Dunbar GC: The Mini-International Neuropsychiatric Interview (M.I.N.I.): the development and validation of a structured diagnostic psychiatric interview for DSM-IV and ICD-10. J Clin Psychiatry 1998, 59(20):22-33. quiz 34-57.

42. Posner K, Oquendo MA, Gould M, Stanley B, Davies M: Columbia Classification Algorithm of Suicide Assessment (C-CASA): classification of suicidal events in the FDA's pediatric suicidal risk analysis of antidepressants. Am J Psychiatry 2007, 164:1035-1043.

43. Derogatis LR, Melisaratos $N$ : The Brief Symptom Inventory: an introductory report. Psychol Med 1983, 13:595-605.

44. McLellan AT, Kushner H, Metzger D, Peters R, Smith I, Grissom G, Pettinati H, Argeriou M: The fifth edition of the addiction severity index. J Subst Abuse Treat 1992, 9:199-213.

45. Saunders JB, Aasland OG, Babor TF, de la Fuente JR, Grant M: Development of the Alcohol Use Disorders Identification Test (AUDIT): WHO collaborative project on early detection of persons with harmful alcohol consumption-II. Addiction 1993, 88:791-804.

46. Cooper TV, DeBon MW, Stockton M, Klesges RC, Steenbergh TA, Sherrill-Mittleman D, Jennings LC, Johnson KC: Correlates of adherence with transdermal nicotine. Addict Behav 2004, 29:1565-1578.

47. U.S. Food and Drug Administration: Information for healthcare professionals: varenicline (marketed as chantix) and bupropion (marketed as Zyban, Wellbutrin, and generics). http://www.fda.gov/Drugs/DrugSafety/Postmarket DrugSafetyInformationforPatientsandProviders/DrugSafetylnformationfor HeathcareProfessionals/ucm169986.htm.

48. Stapleton JA, Watson L, Spirling LI, Smith R, Milbrandt A, Ratcliffe M, Sutherland $\mathrm{G}$ : Varenicline in the routine treatment of tobacco dependence: a pre-post comparison with nicotine replacement therapy and an evaluation in those with mental illness. Addiction 2008, 103:146-154.

49. McClure JB, Swan GE, Jack L, Catz SL, Zbikowski SM, McAfee TA, Deprey M, Richards J, Javitz H: Mood, side-effects and smoking outcomes among persons with and without probable lifetime depression taking varenicline. J Gen Intern Med 2009, 24:563-569.

50. Shim JC, Jung DU, Jung SS, Seo YS, Cho DM, Lee JH, Lee SW, Kong BG, Kang JW, Oh MK, Kim SD, McMahon RP, Kelly DL: Adjunctive varenicline treatment with antipsychotic medications for cognitive impairments in people with schizophrenia: a randomized double-blind placebo-controlled trial. Neuropsychopharmacology 2012, 37:660-668.

51. Williams JM, Anthenelli RM, Morris CD, Treadow J, Thompson JR, Yunis C, George TP: A randomized, double-blind, placebo-controlled study evaluating the safety and efficacy of varenicline for smoking cessation in patients with schizophrenia or schizoaffective disorder. J Clin Psychiatry 2012, 73:654-660.

52. Dutra SJ, Stoeckel LE, Carlini SV, Pizzagalli DA, Evins AE: Varenicline as a smoking cessation aid in schizophrenia: effects on smoking behavior and reward sensitivity. Psychopharmacology (Berl) 2012, 219:25-34. 
53. Garza D, Murphy M, Tseng LJ, Riordan HJ, Chatterjee A: A double-blind randomized placebo-controlled pilot study of neuropsychiatric adverse events in abstinent smokers treated with varenicline or placebo. Biol Psychiatry 2011, 69:1075-1082.

54. Gibbons RD, Mann JJ: Varenicline, smoking cessation, and neuropsychiatric adverse events. Am J Psychiatry 2013, 170:1460-1467.

55. Anthenelli RM, Morris C, Ramey TS, Dubrava SJ, Tsilkos K, Russ C, Yunis C: Effects of varenicline on smoking cessation in adults with stably treated current or past major depression: a randomized trial. Ann Intern Med 2013, 159:390-400.

56. Evins AE, Cather C, Pratt SA, Pachas GN, Hoeppner SS, Goff DC, Achtyes ED, Ayer D, Schoenfeld DA: Maintenance treatment with varenicline for smoking cessation in patients with schizophrenia and bipolar disorder: a randomized clinical trial. JAMA 2014, 311:145-154.

57. Nahvi S, Ning Y, Segal KS, Richter KP, Arnsten JH: Varenicline efficacy and safety among methadone maintained smokers: A randomized placebocontrolled trial. Addiction 2014, [epub ahead of print].

doi:10.1186/1940-0640-9-9

Cite this article as: Nahvi et al:: Rationale and design of a randomized controlled trial of varenicline directly observed therapy delivered in methadone clinics. Addiction Science \& Clinical Practice 2014 9:9.

\section{Submit your next manuscript to BioMed Central and take full advantage of:}

- Convenient online submission

- Thorough peer review

- No space constraints or color figure charges

- Immediate publication on acceptance

- Inclusion in PubMed, CAS, Scopus and Google Scholar

- Research which is freely available for redistribution 